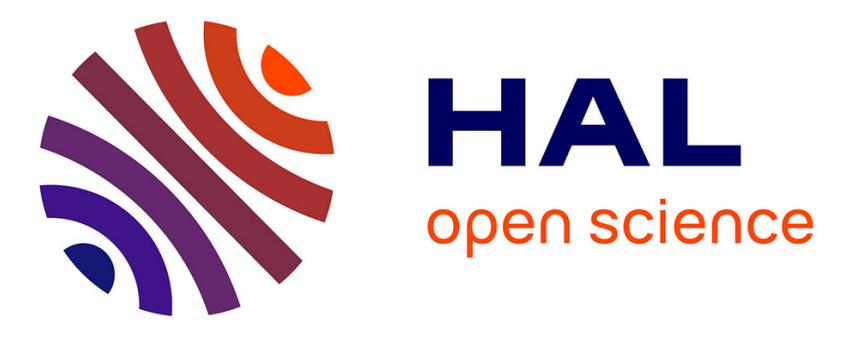

\title{
Depletion of the p43 mitochondrial T3 receptor in mice affects skeletal muscle development and activity.
}

Laurence Pessemesse, Audrey Schlernitzauer, Chamroeun Sar, Jonathan

Levin, Stéphanie Grandemange, Pascal Seyer, François Bertrand Favier, Sandra Kaminski, Gérard Cabello, Chantal Wrutniak Cabello, et al.

\section{To cite this version:}

Laurence Pessemesse, Audrey Schlernitzauer, Chamroeun Sar, Jonathan Levin, Stéphanie Grandemange, et al.. Depletion of the p43 mitochondrial T3 receptor in mice affects skeletal muscle development and activity.. FASEB Journal, 2012, 26 (2), pp.748-756. 10.1096/fj.11-195933 . hal-00746541

\section{HAL Id: hal-00746541 \\ https://hal.science/hal-00746541}

Submitted on 29 May 2020

HAL is a multi-disciplinary open access archive for the deposit and dissemination of scientific research documents, whether they are published or not. The documents may come from teaching and research institutions in France or abroad, or from public or private research centers.
L'archive ouverte pluridisciplinaire HAL, est destinée au dépôt et à la diffusion de documents scientifiques de niveau recherche, publiés ou non, émanant des établissements d'enseignement et de recherche français ou étrangers, des laboratoires publics ou privés. 


\title{
Depletion of the p43 mitochondrial T3 receptor in mice affects skeletal muscle development and activity
}

\author{
Laurence Pessemesse, ${ }^{*}{ }^{\dagger}$ Audrey Schlernitzauer, ${ }^{*}{ }^{\dagger}$ Chamroeun Sar, ${ }^{\dagger,}$ Jonathan Levin, ${ }^{*}, \dagger$ \\ Stéphanie Grandemange, ${ }^{*,+, 1}$ Pascal Seyer, ${ }^{*},+1$ François B. Favier, ${ }^{*}, \dagger$ \\ Sandra Kaminski, ${ }^{*},{ }^{\dagger}, 1$ Gérard Cabello, ${ }^{*},{ }^{\dagger}$ Chantal Wrutniak-Cabello, ${ }^{*}, \dagger$ \\ and François Casas ${ }^{*},+2$ \\ *Institut National de Recherche Agronomique (INRA), Unité Mixte de Recherche (UMR) 866 \\ Dynamique Musculaire et Métabolisme, Montpellier, France; ${ }^{\dagger}$ Université Montpellier 1 and \\ Université Montpellier 2, Montpellier, France; and ${ }^{\ddagger}$ Institut National de la Santé et de la Recherche \\ Médicale (INSERM), U-583, Institut des Neurosciences de Montpellier, Hôpital Saint Eloi-80 \\ Montpellier, France
}

ABSTRACT In vertebrates, skeletal muscle myofibers display different contractile and metabolic properties associated with different mitochondrial content and activity. We have previously identified a mitochondrial triiodothyronine receptor $(\mathrm{p} 43)$ regulating mitochondrial transcription and mitochondrial biogenesis. When overexpressed in skeletal muscle, it increases mitochondrial DNA content, stimulates mitochondrial respiration, and induces a shift in the metabolic and contractile features of muscle fibers toward a slower and more oxidative phenotype. Here we show that a p43 depletion in mice decreases mitochondrial DNA replication and respiratory chain activity in skeletal muscle in association with the induction of a more glycolytic muscle phenotype and a decrease of capillary density. In addition, $\mathrm{p} 43^{-/-}$mice displayed a significant increase in muscle mass relative to control animals and had an improved ability to use lipids. Our findings establish that the p43 mitochondrial receptor strongly affects muscle mass and the metabolic and contractile features of myofibers and provides evidence that this receptor mediates, in part, the influence of thyroid hormone in skeletal muscle.-Pessemesse, L., Schlernitzauer, A., Sar, C., Levin, J., Grandemange, S., Seyer, P., Favier, F. B., Kaminski, S., Cabello, G., WrutniakCabello, C., Casas, F. Depletion of the p43 mitochondrial T3 receptor in mice affects skeletal muscle development and activity. FASEB J. 26, 000-000 (2012). www.fasebj.org

Key Words: metabolism • thyroid hormone

Skeletal muscle contains myofibers differing in contractile function, mitochondrial content, and consequently metabolic properties. Slow-twitch fibers are characterized by type I myosin heavy chain (MyHC) expression and a high mitochondrial density leading to a prominent oxidative metabolism. Fast-twitch fibers express type II MyHCs including 3 subtypes: IIa, IIx, and IIb. IIb fibers display a reduced mitochondrial density and a major glycolytic metabolism. The oxidative capacity of type IIa and IIx fibers is intermediate between that recorded in type I and $\operatorname{IIb}$ fibers $(1,2)$. Adult skeletal muscle displays some plasticity, allowing conversion of contractile and metabolic fiber types in response to changes in contractile activity (1).

Like other tissues, skeletal muscle is an important target of thyroid hormones. Indeed, triiodothyronine (T3) is considered as a regulator of in vivo muscle development. It does not only stimulate growth by increasing the number and diameter of muscle fibers $(3,4)$, but it is also involved in the transition between neonatal and adult myosin isoforms (5) and could affect the metabolic and contractile features of adult muscle fibers (6).

For a while, it was assumed that thyroid hormone acts uniquely through a nuclear receptor encoded by $\mathrm{TR} \alpha$ and TR $\beta$ genes $(7,8)$. However, we $(9,10)$ previously identified in the mitochondrial matrix a $43-\mathrm{kDa}$ truncated form of the nuclear receptor TR $\alpha 1$ (p43) synthesized by the use of an internal initiation site of translation occurring in the $\mathrm{TR} \alpha 1$ transcript. $\mathrm{p} 43$ is a mitochondrial T3 receptor ubiquitously expressed that stimulates mitochondrial transcription and protein synthesis in the presence of T3 (11). In avian QM7 myoblasts or murine C2C12 cells, p43 overexpression stimulates mitochondrial activity and potentiates terminal differentiation, whereas direct inhibition of this pathway induces the reverse changes through the con-

\footnotetext{
${ }^{1}$ Current address: S.G., EA4421 SIGReTO Université Henri Poincaré BP70239, F-54506 Vandoeuvre Les Nancy, France; P.S., Institut de Génomique Fonctionnelle, 141 rue de la Cardonille, F-34094 Montpellier, France; S.K., Department for Medical Genetics, Molecular and Clinical Pharmacology, Medical University of Innsbruck, Austria.

${ }^{2}$ Correspondence: INRA, UMR-866 Dynamique Musculaire et Métabolisme, 2 place Viala, F-34060 Montpellier, France; and Université Montpellier 1, Montpellier, France; Université Montpellier 2, F-34060 Montpellier, France. E-mail: casasf@ supagro.inra.fr

doi: $10.1096 /$ fj.11-195933
} 
trol of myogenin, c-Myc, and calcineurin expression (12-14). Recently, we have shown in vivo that $\mathrm{p} 43$ overexpression in skeletal muscle increases mitochondrial $(\mathrm{mt})$ DNA content, increases mitochondrial respiration, and induces a shift in metabolic and contractile features of muscle fibers toward a slower and more oxidative phenotype (15). However, this overexpression also induced a potent oxidative stress leading to skeletal muscle atrophy during aging (16).

To further investigate the physiological importance of $\mathrm{p} 43$, we generated mice specifically depleted of $\mathrm{p} 43$ but still expressing the full-length TR $\alpha 1$ nuclear receptor, $\mathrm{TR} \alpha 2$, and other $\mathrm{TR} \alpha$ proteins (17). In metabolic studies, we initially found that p43 depletion in mice induced a loss of glucose-stimulated insulin secretion, demonstrating that this mitochondrial T3 receptor is an important regulator of pancreatic $\beta$-cell function and of glucose homeostasis.

In this work, we focused our study on skeletal muscle, and we report that $\mathrm{p} 43$ depletion in mice increases muscle mass and reduces the amounts of mtDNA and the maximal activities of respiratory complexes. In addition, it decreases muscle capillary density and induces a shift toward a faster and more glycolytic muscle fiber phenotype. Furthermore, $\mathrm{p} 43^{-/-}$mice had a better capacity to use lipids. These data show that the direct T3 mitochondrial pathway strongly affects muscle mass and the metabolic and contractile features of myofibers.

\section{MATERIALS AND METHODS}

\section{Animals}

All animal experiments were performed according to European directives (86/609/CEE) and approved by the Comite d'Ethique en Matière d'Expérimentation Animale: Région Languedoc-Roussillon. Our institutional guidelines for the care and use of laboratory animals were observed. The $\mathrm{p} 43^{-/-}$mice, lacking specifically the mitochondrial T3 receptor $\mathrm{p} 43$, were generated by our team as described previously (17). All the mice used in these studies were back-crossed $>10$ times into the C57BL/ 6 background. We generated our colony by crossing $\mathrm{p} 43^{-/-}$mice with wild-type (WT) C57BL/ 6 breeders and generated future generations of WT controls. Experiments were performed in 5-mo-old males.

\section{Metabolic analysis}

Oxygen consumption, carbon dioxide production, and respiratory exchange ratio (RER) were measured at $22^{\circ} \mathrm{C}$ using a Comprehensive Lab Animal Monitoring System (Columbus Instruments, Columbus, OH, USA). Male mice were acclimatized individually in metabolic cages with ad libitum access to standard chow and water for $24 \mathrm{~h}$ before a $7 \mathrm{~h}$ period of automated recordings in unfed condition. Sample air from individual cages was passed through sensors to determine $\mathrm{O}_{2}$ and $\mathrm{CO}_{2}$ content. The RER was calculated as the ratio between $\mathrm{CO}_{2}$ production and $\mathrm{O}_{2}$ consumption.

\section{Treadmill studies}

Treadmill exercise tests were performed using a motorized rodent treadmill equipped with a shock-plate incentive
(Exer-6M Open Treadmill; Columbus Instruments). Before the exercise performance test, the mice were accustomed to the treadmill with a 5 -min run at $7 \mathrm{~m} / \mathrm{min}$ for $2 \mathrm{~d}$. For prolonged exercises of low intensities, the exercise test regimen was 10 $\mathrm{m} / \mathrm{min}$ for the first $60 \mathrm{~min}$, followed by $1 \mathrm{~m} / \mathrm{min}$ increment at 15 min intervals as described previously $(16,18)$. Exhaustion was defined when mice were unable to avoid repetitive electrical shocks. To evaluate the peak velocity (PV) at maximal oxygen consumption $\left(\mathrm{VO}_{2 \max }\right)$, the exercise test regimen was $10 \mathrm{~m} / \mathrm{min}$ for the first minute, followed by $2 \mathrm{~m} / \mathrm{min}$ increments every 2 min until $14 \mathrm{~m} / \mathrm{min}$, then $1 \mathrm{~m} / \mathrm{min}$ every minute.

\section{Histological analysis}

Fresh muscles were immersed in a solution of $3.5 \%$ glutaraldehyde in phosphate buffer $(0.1 \mathrm{M}, \mathrm{pH} 7.4)$ overnight at $4^{\circ} \mathrm{C}$. They were then rinsed in phosphate buffer and postfixed (1\% osmic acid and $0.8 \%$ potassium ferrocianide) for $2 \mathrm{~h}$ in the dark and at room temperature. After 2 rinses in a phosphate buffer, muscles were dehydrated in a graded series of ethanol solutions (30$100 \%$ ). The cells were embedded in EmBed 812 DER 736 (Electron Microscopy Sciences, Hatfield, PA, USA). Thin sections (85 nm; Leica-Reichert Ultracut E; Leica Microsystems, Wetzlar, Germany) were collected at different levels of each block. These sections were counterstained with uranyl acetate and lead citrate and observed using a Hitachi 7100 transmission electron microscope (Hitachi, Tokyo, Japan) in the Centre de Resources en Imagerie Cellulaire de Montpellier (Montpellier, France).

For all other histologies, fresh muscle was collected, embedded with optimum cutting temperature (OCT) medium matrix (Sakura Finetek, Torrance, CA, USA), and immediately frozen in isopentane cooled in liquid nitrogen. Serial transverse sections $(10 \mu \mathrm{m}$ in thickness) were cut with a cryostat microtome. Some sections were then stained with azorubine $1 \%$ to allow quantification of fiber number and area collected from tibialis muscle or with alkaline phosphatase to label skeletal muscle capillaries. Briefly, for histochemistry of alkaline phosphatase, sections were incubated in 270 $\mu \mathrm{M}$ 5-bromo-4-chloro-3-indolyl phosphate and in $50 \mu \mathrm{M}$ nitro blue tetrazolium for $20 \mathrm{~min}$ at $37^{\circ} \mathrm{C}$, washed in PBS 1 time, and fixed with $5.7 \%$ formaldehyde. Muscle sections were scanned using a NanoZoomer (Hamamatsu Photonics, Hamamatsu City, Japan) with a $\times 20$ objective. Definiens Developer 7.1. software (Definiens, Munich, Germany) was used to analyze the pictures for each entire area. To determine the capillary density and quantify the tibialis fiber number and area, we analyzed 2 sections/muscle. For these studies, muscles from $7 \mathrm{p} 43^{-/-}$and WT mice were used.

\section{Assessment of mtDNA copy number}

mtDNA content is the mtDNA copy number normalized to the copy number of a nuclear gene. After extraction of muscle DNA, quantitative PCR reactions were performed in the presence of fluorescent dye (SYBR Green; Bio-Rad, Hercules, CA, USA) using ND5 for mtDNA copy estimation and $18 \mathrm{~S}$ for the nuclear genome (15). All results are expressed as mean \pm SE percentage of control. Student's $t$ test was used to determine all $P$ values.

\section{Gene expression studies}

Total RNA was isolated from quadriceps muscle using the Trizol method (Invitrogen, Carlsbad, CA, USA). Samples were reverse transcribed using SuperScript first-strand synthesis system (Invitrogen), and quantitative PCR reactions were performed in the presence of fluorescent dye (SYBR Green; 
Bio-Rad). The primers previously described were used (15). Results were normalized by RPS9 and are expressed as means \pm se. Student's $t$ test were used to determine all $P$ values.

\section{Enzymatic activities of mitochondrial complexes}

Enzymatic activities were measured from quadriceps muscle homogenates prepared at $4^{\circ} \mathrm{C}$ in $500 \mu$ l phosphate buffer $(50$ $\mathrm{mm}$; pH 7) using a Polytron homogenizer. Complex I activity in supernatant fraction were determined spectrophotometrically as described previously (19). Complex II activity was measured spectrophotometrically as described previously (20). Complex IV or cytochrome $c$ oxidase activity was measured spectrophotometrically as described previously (21). Protein concentrations were measured using the Bio-Rad protein assays kit.

\section{Statistical analysis}

All results are presented as means \pm SE or as percentages of control values. Significance of the differences between groups was evaluated using the Student's $t$ test. Values of $P<0.05$ were considered significant.

\section{RESULTS}

$\mathrm{p} 3^{-/-}$mice exhibit an increase in muscle mass and a decrease in respiratory complex maximal activity

At 5 mo of age, body weights of $\mathrm{p} 43^{-/-}$mice were slightly smaller compared with WT animals (31.3 vs.
32.6 g; $n=17$ /group; $P<0.05$; Fig. $1 A$ ). However, an increase in muscular mass in $\mathrm{p} 43^{-/-}$mice was attested by a higher quadriceps muscle weight (253 vs. $225 \mathrm{mg}$; $P<0.001$; Fig. $1 B$ ) and the higher value observed after normalization to the weight (Fig. 1C).

We have previously shown that p43 stimulates mitochondrial respiratory chain activity $(9,11,15)$. In agreement with these data, 5-mo-old $\mathrm{p} 43^{-/-}$mice displayed a potent inhibition of the maximal activity of complexes I $(-47 \% ; P<0.01)$ and IV $(-54 \% ; P<0.001)$ and a smaller reduction of complex II maximal activity $(-21 \% ; P<0.05$; Fig. $1 D-F)$. These data suggest that p43 depletion induces a defect in respiratory chain activities in skeletal muscle.

\section{mtDNA content decreases in $\mathrm{p} 43^{-/-}$mice}

Mitochondrial biogenesis in quadriceps muscle, assessed by the ratio mtDNA (ND5 ${ }^{-/-}$nuclear DNA (18S), was reduced up to 2-fold in 5-mo-old $\mathrm{p} 43^{-/-}$ mice (Fig. 2A), in agreement with the slight but significant decrease in citrate synthase maximal activity (Fig. $2 B)$, considered as another marker of the mitochondrial mass.

Electron microscopy studies of muscle from $\mathrm{p} 43^{-/-}$ animals showed enlarged mitochondria compared with control mice (Fig. 2C). To better understand these observations, we investigated the expression of genes regulating mitochondrial biogenesis. In the quadriceps muscle of $\mathrm{p} 43^{-/-}$mice, peroxisome proliferator-activated recep-
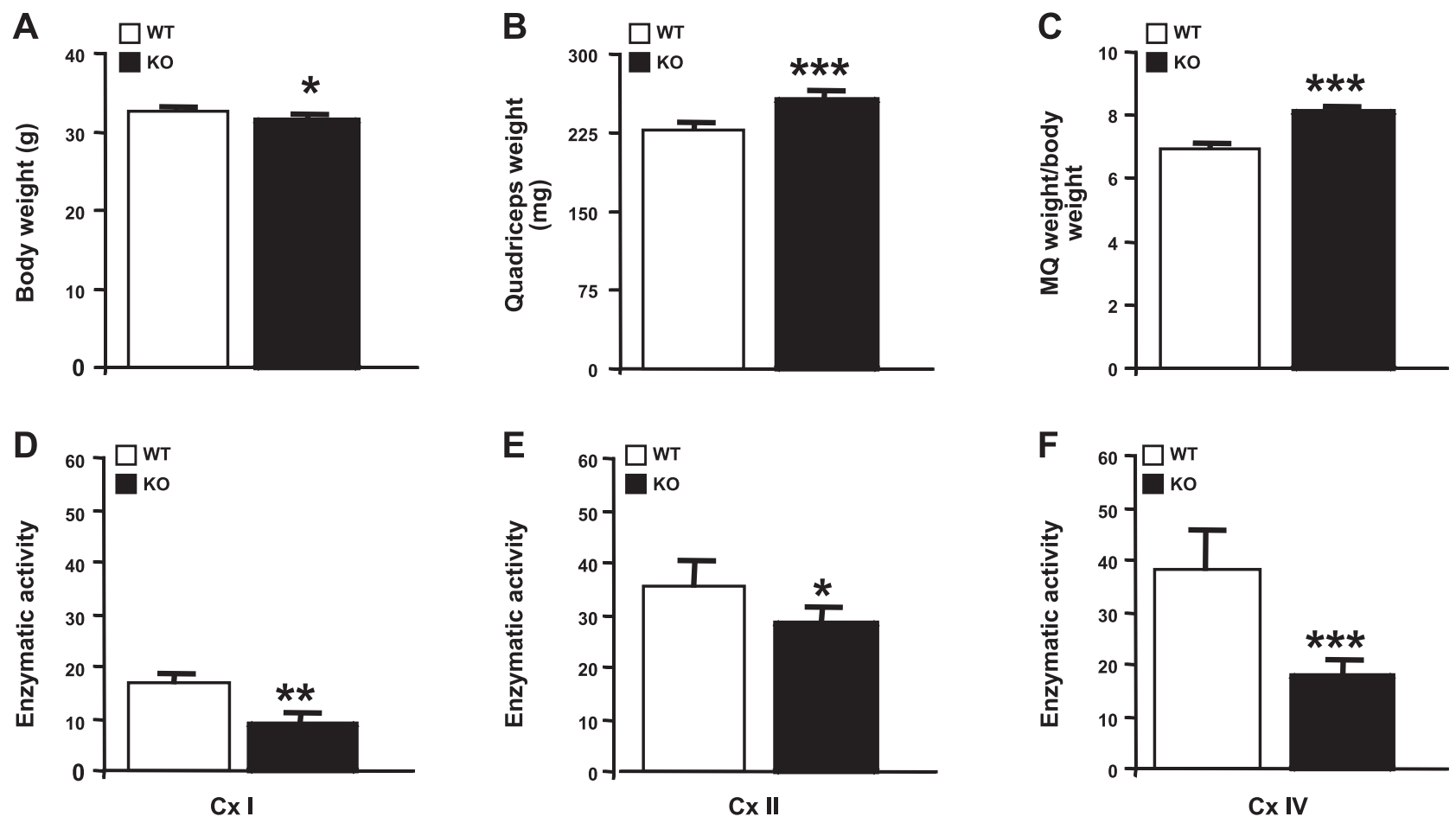

Figure 1. $443^{-/-}$mice display an increased muscle mass and a decreased maximal activity the respiratory chain complexes. $\left.A\right)$ Body weights in 5-mo-old male mice ( $n=26$ /group). B) Quadriceps weights in 5-mo-old male mice $(n=17 /$ group). $C$ ) Quadriceps weights in 5-mo-old male mice related to body weights $(n=17 /$ group). $D-F)$ Mitochondrial complex $(\mathrm{Cx})$ I $(D)$, II $(E)$, and IV $(F)$ maximal activities recorded on quadriceps muscle extracts from controls and $\mathrm{p} 43^{-/-}$mice at 5 mo of age $(n=8 /$ group $)$. KO, knockout. Error bars $=\mathrm{SE} . * P<0.05, * * P<0.01, * * * P<0.001$; Student's $t$ test. 
A
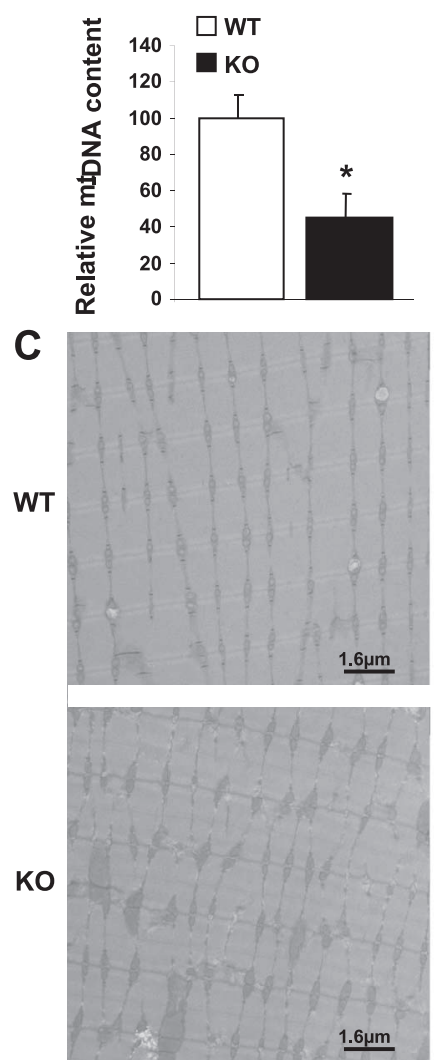

\section{B}
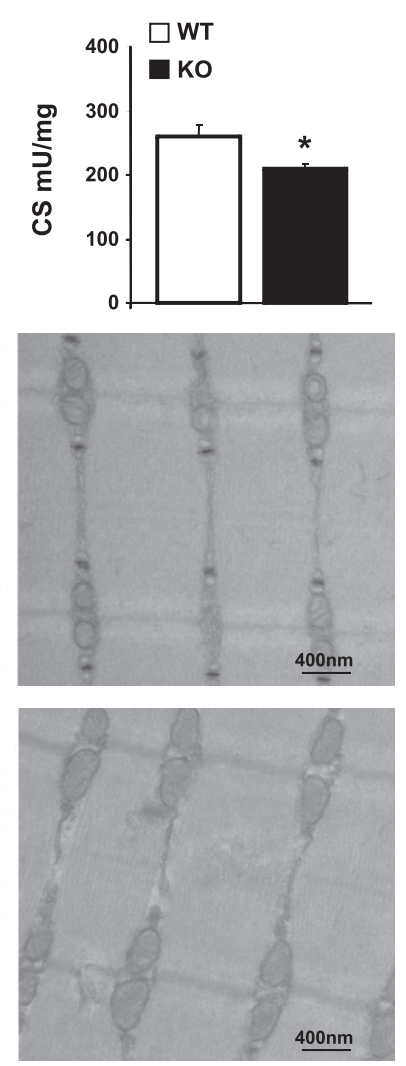

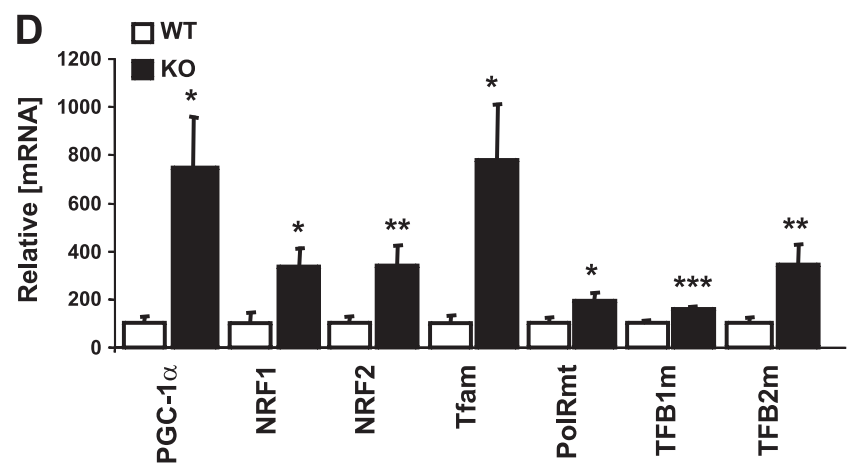

E

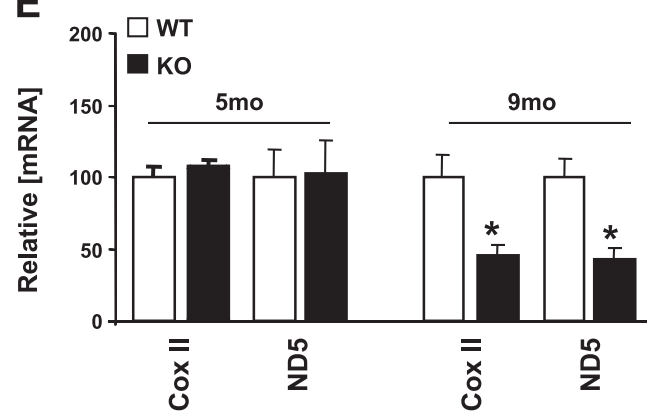

Figure 2. p43 depletion in mice reduces mtDNA content. A) Relative mtDNA content (ND5/18S) in quadriceps from control and $\mathrm{p} 43^{-/-}$mice at 5 mo of age $(n=8 /$ group). After extraction of muscle DNA, quantitative PCR reactions were performed using ND5 for mtDNA copy estimation and 18S for the nuclear genome. $B$ ) Citrate synthase maximal activity measured in quadriceps muscle extracts from control and $\mathrm{p} 43^{-/-}$mice at 5 mo of age $(n=8 /$ group $)$. C) Electron microscopy experiments from longitudinal sections taken from control and $\mathrm{p} 43^{-/-} 5$-mo-old mice quadriceps $(n=3$ /group; view $\times 10,000)$. $\left.D\right)$ Relative mRNA expression levels of genes regulating mitochondrial biogenesis in quadriceps from control and $\mathrm{p} 43^{-/-}$mice at 5 mo of age $(n=8 /$ group). $E$ ) Relative mRNA expression levels of mitochondrial transcripts in quadriceps from control and p $43^{-\prime-}$ mice at 5 and 9 mo of age ( $n=8$ /group). Values obtained in $\mathrm{p} 3^{-/-}$mice are expressed as percentage of the corresponding control value. Error bars $=$ SE. $* P<0.05, * * P<0.01, * * * P<0.001$; Student's $t$ test.

tor- $\alpha$ coactivator-1 (PGC-1 $\alpha ;+650 \% ; P<0.05)$, nuclear respiratory factor 1 (NRF1; $+236 \% ; P<0.05)$, NRF2 $(+241 \% ; P<0.01)$, mitochondrial transcription factors A (Tfam; $+678 \% ; P<0.01$ ) and B2 (TFB2m; $+244 \%$; $P<0.01)$, and, more moderately, mitochondrial RNA polymerase (PolMRT; $+96 \% ; P<0.01)$ and mitochondrial transcription factor B1 (TFB1m; $+58 \% ; P<0.001$; Fig. 2D) were up-regulated when compared with control animals. However, this strong increase in the expression of genes involved in mitochondrial biogenesis is clearly not sufficient to recover a normal level of mtDNA content in $\mathrm{p} 43^{-/-}$mice. These data led us to conclude that $\mathrm{p} 43$ is a key regulator of mtDNA copy number in the muscle. Last, we found that the mitochondrial transcript levels (CoxII and ND5) in the quadriceps muscle of $\mathrm{p} 43^{-/-}$mice were reduced at the age of 9 mo $(-57$ and $-53 \%$, respectively; $P<0.05$ ) but not at 5 mo (Fig. $2 E$ ).

\section{Depletion of p43 induces muscle hypertrophy}

To better understand the increase in muscle mass observed in $\mathrm{p} 43^{-/-}$mice, we examined the cross-sectional area of tibialis muscle from $\mathrm{p} 43^{-/-}$mice and control animals. To visualize the muscle fibers, an azorubine staining was used. The number and area of tibialis fibers were quantified with Definiens Developer 7.1 software after a nanozoomer scan (Fig. 3A). Quantification of the number and area of tibialis fibers indicated that in $\mathrm{p} 43^{-/-}$mice, the mean cross-sectional area was significantly higher than in control animals $(+23 \% ; P<0.05)$ without any statistical change in the total fiber numbers (4068 vs. 3957 fibers; Fig. 3B, C). However, analysis of the number of fibers in each range of area indicated that hypertrophy was only restricted to the largest fibers $\left(>3500 \mu \mathrm{m}^{2}\right.$; 378 vs. 214 fibers; $P<0.01$; Fig. 3D). In addition, the number of fibers with an area $<500 \mu \mathrm{m}$ was also increased by p43 depletion (621 vs. 444 fibers; $P<0.05$; Fig. $3 D$ ). Taken together, these data indicated that $\mathrm{p} 43$ deletion induced a muscular hypertrophy by increasing the number of the biggest fibers but without changing the total number of fibers.

\section{p43 depletion induces a shift toward a fast fiber phenotype}

To determine whether the decrease of mitochondrial activity was associated with a fiber type switch, we measured the expression of the 4 adult MyHC tran- 
A

WT

KO

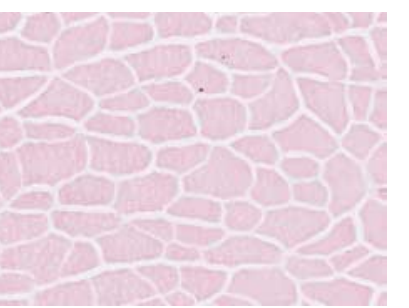

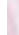

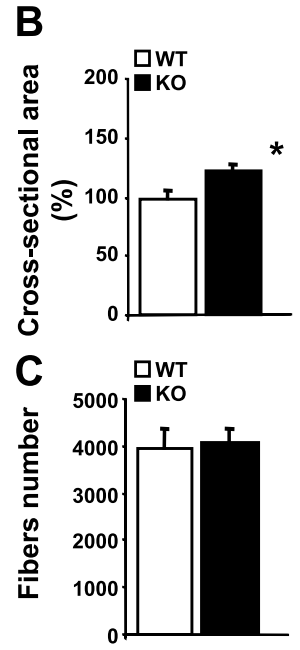

D

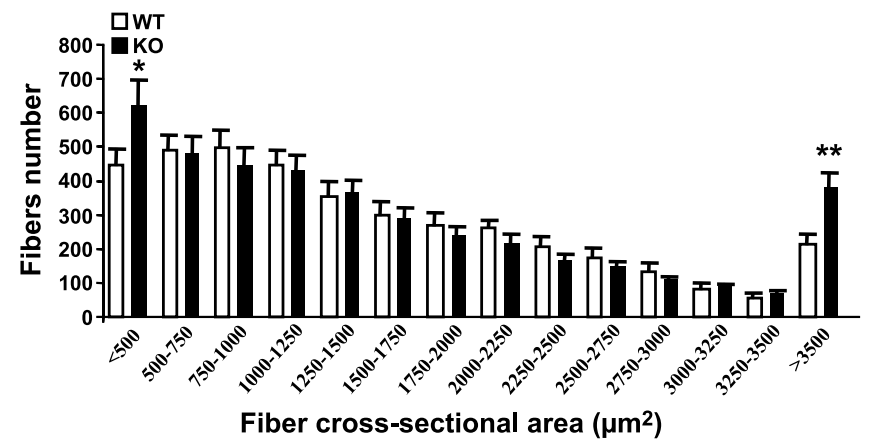

Figure 3. p43 depletion induces muscle hypertrophy in mice. A) Azorubine staining of tibialis muscle sections used to quantify the number and areas of fibers. Muscle sections were scanned using a NanoZoomer (Hamamatsu Photonics) with a $\times 20$ objective. $B-D$ ) Definiens Developer 7.1 software was used to analyze the images for each entire area and for the quantification. $B$ ) Relative cross-sectional area of tibialis muscle from control and $\mathrm{p} 43^{->-}$mice at 5 mo of age $(n=7 /$ group $)$. Values obtained in $\mathrm{p} 43^{-/-}$mice are expressed as percentage of the corresponding control value. C) Fiber numbers in tibialis muscle from control and p43 ${ }^{-1-}$ mice at 5 mo of age $\left(n=7 /\right.$ group). D) Fiber size distribution from controls and $\mathrm{p} 43^{-/-}$mice at 5 mo of age $(n=7 /$ group $)$. Error bars $=$ SE. $* P<0.05, * * P<0.01$; Student's $t$ test. scripts by quantitative PCR. In quadriceps, an oxidoglycolytic muscle, a higher expression of MyHCIIx $(+336 \% ; P<0.001)$ and lower expression of MyHCIIa $(-68 \% ; P<0.01)$ were observed in $\mathrm{p} 43^{-/-}$mice (Fig. $\left.4 A\right)$. In soleus, a muscle with an abundance of type I and type IIa fibers, the expression of MyHC-IIa was increased by 443 depletion $(+153 \%$; $P<0.05)$, whereas MyHC type I expression was reduced $\mathrm{p} 43^{-/-}$mice $(-30 \% ; P<0.05$; Fig. $4 B)$. These findings were consistent with the decrease in mitochondrial activity previously described, indicating that a switch to a more glycolytic phenotype occurred in $\mathrm{p} 43^{-/-}$mice.

\section{$\mathrm{p}^{4} 3^{-/-}$mice had a lower capillary density in skeletal muscle}

The capillary supply of a muscle fiber is generally associated with its type, oxidative capacity, and size. Because depletion of p43 significantly affects the metabolic and contractile fiber phenotype, we assessed the capillary density in tibialis muscle from $\mathrm{p} 43^{-/-}$mice and control animals. After the microvessel network was stained with alkaline phosphatase (Fig. 5A), a significant decrease of capillary density was observed in $\mathrm{p} 43^{-/-}$mice relative to controls $(-51 \% ; P<0.01$; Fig. $5 B)$, in the presence of unaffected hematocrit values (Fig. 5C).

\section{$\mathrm{p} 43^{-/-}$mice have reduced peak velocity at maximal oxygen consumption}

Muscle metabolic and contractile capacity partly determines endurance and fatigability. We thus compared exercise performance using weight-matched $\mathrm{p} 43^{-/-}$ mice and controls animals (Fig. 6A). We performed an incremental exercise test until exhaustion to determine $\mathrm{PV}$ at maximal oxygen consumption $\left(\mathrm{Vo}_{2 \max }\right)$. As ex- pected, $\mathrm{p} 43^{-/-}$mice displayed a reduced PV compared with controls (25.5 vs. $30.5 \mathrm{~m} / \mathrm{min}$, respectively; $P<0.05$; Fig. $6 B$ ).

We also compared exercise performance on treadmills, as described previously $(16,18)$. The exercise test regimen is described in Materials and Methods. Surprisingly, when faced with prolonged exercise at low intensities, $\mathrm{p} 43^{-/-}$mice ran twice the distance and ran twice the time observed for WT mice (Fig. $6 C, D$ ).

\section{p $43^{-/-}$mice had a better capacity to use lipids}

Lipid oxidation is the main energetic pathway used in prolonged exercise of low intensity. The improved endurance observed in $\mathrm{p} 43^{-/-}$mice led us to study the ability of these animals to oxidize lipids. The RER $\left(\mathrm{RER}=\mathrm{VCO}_{2} / \mathrm{VO}_{2}\right)$ was used to estimate the contribution of fat and carbohydrate to whole-body energy metabolism in mice in vivo. We found that the RER recorded in $\mathrm{p} 43^{-/-}$mice was significantly lower than that recorded in WT animals (Fig. 7A, B) as previously shown for full TR $\alpha$-deficient mice (Thra-0/0; ref. 22). Because skeletal muscle is a major site for fuel metabolism, this result suggests that in the unfed state, muscle from $\mathrm{p} 43^{-/-}$mice used more fat as a fuel contribution to exercise than WT mice. In line with these results, blood free fatty acid levels were higher in $\mathrm{p} 43^{-/-}$mice than in control mice $(+29 \% ; P<0.05$; Fig. $7 C)$. Moreover, lipoprotein lipase mRNA levels were consistently up-regulated in quadriceps muscle $(+155 \% ; P<0.01$; Fig. $7 D)$.

\section{DISCUSSION}

\section{Influence of p43 on mitochondrial activity}

We have previously shown that in avian and murine myoblast lines, p43 overexpression stimulates mito- 

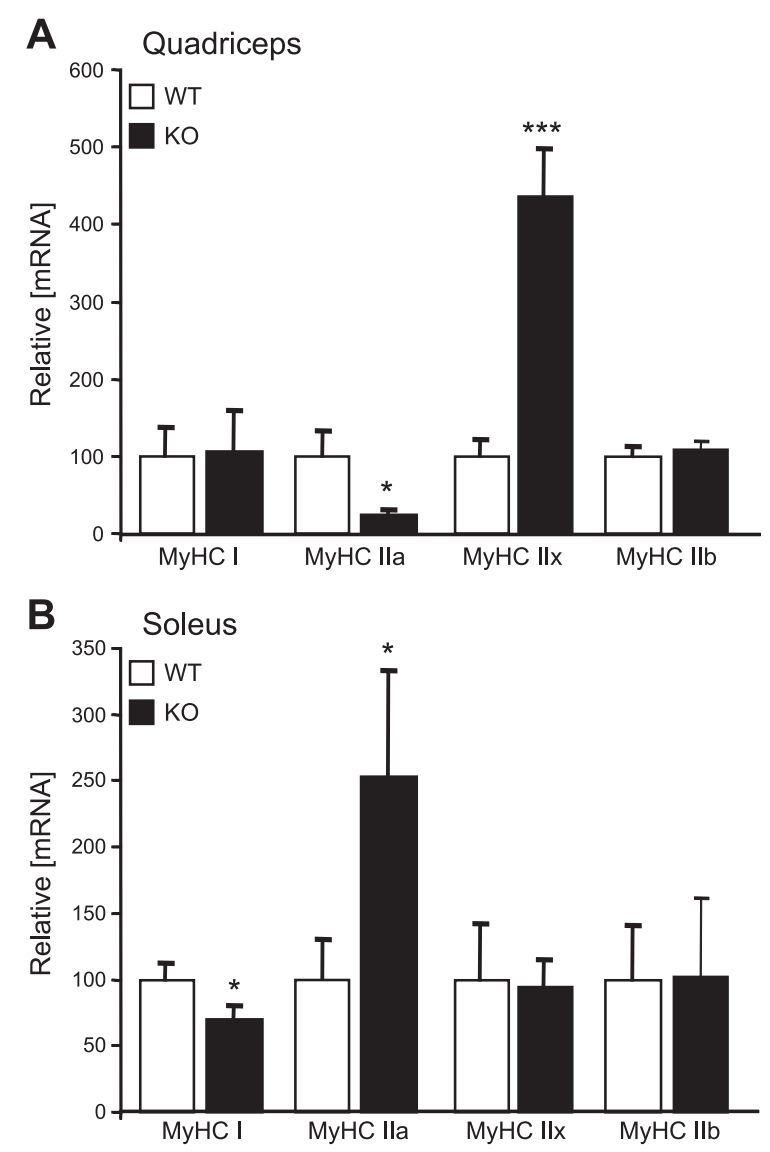

Figure 4. p43 depletion induces a shift toward a fast contractile phenotype. Relative mRNA expression levels of the 4 adult MyHC isoforms in quadriceps $(A)$ or soleus $(B)$ muscles from control and $\mathrm{p} 43^{-/-}$mice at 5 mo of age ( $n=8 /$ group). Values obtained in $\mathrm{p} 3^{-/-}$mice are expressed as percentage of the corresponding control value. Error bars $=\mathrm{SE} . * P<$ $0.05, * * * P<0.001$; Student's $t$ test.

chondrial activity and potentiates their terminal differentiation and that inhibition of the p43 pathway induces the reverse effect by targeting myogenin, $c-\mathrm{Myc}$, and calcineurin expression $(12,13)$. More recently, we have confirmed the in vivo importance of $\mathrm{p} 43$ by establishing that $\mathrm{p} 43$ overexpression in mouse skeletal muscle increases mitochondrial transcription and mitochondrial biogenesis. To further investigate the physiological influence of $\mathrm{p} 43$ on muscle, we have generated $\mathrm{p} 43^{-/-}$mice still expressing normal levels of $\mathrm{TR} \alpha 1, \mathrm{TR} \alpha 2$, and other $\mathrm{TR} \alpha$ proteins (17). In the present study, we report that $\mathrm{p} 43$ depletion reduces the maximal activity of several respiratory chain complexes and decreases mtDNA content in skeletal muscle. Taken together, these data demonstrate that p43 is an in vivo regulator of mitochondrial biogenesis. In addition, we established that despite the potent up-regulation of PGC1 $\alpha$ and Tfam mRNA expression in $\mathrm{p} 43^{-/-}$ mice in skeletal muscle, mtDNA content in these animals is still inferior to WT, thus suggesting that besides its mitochondrial transcriptional activity (11), this mitochondrial T3 receptor is also involved in the maintenance of mtDNA. However, in isolated pancreatic islet (17) or in liver (unpublished data), mtDNA content is not significantly affected by the deletion of $\mathrm{p} 43$. These data indicate no general decrease of mtDNA content in $\mathrm{p} 43^{-1-}$ mice. These findings show that the skeletal muscle is more sensitive to p43 effect than pancreatic islet or liver.

Moreover, we showed that $\mathrm{p} 43^{-/-}$mice, despite the reduction of mtDNA copy number, have normal levels of several mitochondrial transcripts at 5 mo of age. The levels of mitochondrial transcripts were reduced in skeletal muscle of $\mathrm{p} 43^{-/-}$mice only at 9 mo of age. This progressive reduction in mitochondrial transcript levels is consistent with up-regulation of mitochondrial RNA and protein stability, as previously shown in Tfam-deficient mice $(23,24)$. Furthermore, studies of cell lines have shown that inhibition of mtDNA expression dramatically increases the stability of mtDNAencoded transcripts and proteins $(25,26)$.

\section{Influence of p43 depletion on muscle phenotype}

We have previously shown that p43 overexpression affects the contractile and metabolic phenotype of mucle fibers (15). In particular, in soleus muscle, MyHC IIa expression was down-regulated in favor of
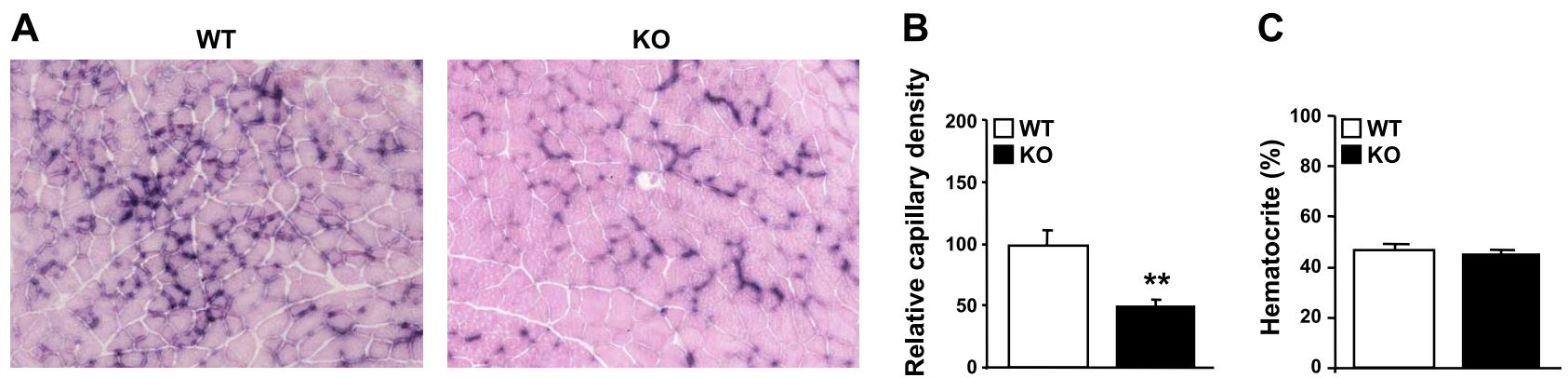

Figure 5. p43 invalidation in mice decreases the capillary density in skeletal muscle. A) Alkaline phosphatase staining of tibialis muscle sections used for the assessment of capillary density. Muscle sections were scanned using a NanoZoomer (Hamamatsu Photonics) with a $\times 20$ objective. $B$ ) Relative capillary density of tibialis muscle from control and p43 ${ }^{-/-}$mice at 5 mo of age ( $n=7$ /group). Definiens Developer 7.1. software was used to analyze each muscle section and for quantification. Values obtained in $\mathrm{p} 43^{-/-}$mice are expressed as percentage of the corresponding control value. C) Hematocrit recorded in blood samples from controls and $\mathrm{p} 43^{-/-}$mice at 5 mo of age $(n=6 /$ group $)$. Error bars $=\mathrm{se} . * * P<0.01$; Student's $t$ test. 

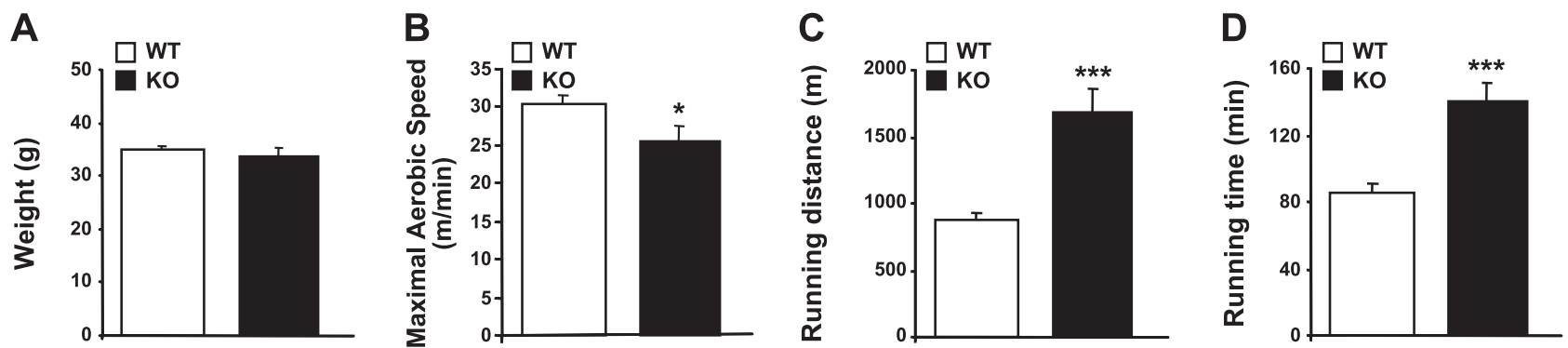

Figure 6. Effect of p43 invalidation on maximal aerobic speed and on the ability to undergo prolonged exercise at low intensities. A) Control and $\mathrm{p} 43^{-/-}$mice at 5 mo of age with similar body weights $(n=6 /$ group) were subjected to a forced treadmill exercise test. B) Maximal aerobic speed recorded from control and $\mathrm{p} 43^{-/-}$mice at 5 mo of age $(n=6 /$ group). $C$, $D)$ Running distance $(C)$ and running time $(D)$ recorded after prolonged exercise at low intensities from control and $\mathrm{p} 43^{-/-}$ mice at 5 mo of age $(n=6 /$ group $)$. Error bars $=\mathrm{sE}$. $* P<0.05$, *** $P<0.001$; Student's $t$ test.

MyHC I expression, whereas in quadriceps muscle an increase of MyHC IIa and IIx expression was associated with a reduction in MyHC IIb expression. In this study, we report that $\mathrm{p} 43$ depletion induced exactly the reverse changes, thus establishing that $\mathrm{p} 43$ regulates muscle fiber phenotype. Indeed, in soleus, MyHC-I expression was down-regulated in favor of MyHC IIa expression, and, in quadriceps, an increase in MyHCIIx expression was associated with a reduction in $\mathrm{MyHC}$ IIa expression. However, these results underline that in a fast twitch muscle (quadriceps) this regulation only affects the MyHC IIa toward IIx transition, and in a slow twitch muscle (soleus), the MyHC I toward IIA transition. This observation, indicating that $\mathrm{MyHC}$ IIb is not affected in these 2 muscles, agrees well with the theory of a limited muscle contractile plasticity (27).

Several studies have reported that the capillary density in skeletal muscle varies with fiber type. Slow muscle fibers have generally a higher capillary density than fast fibers $(28,29)$. This agrees well with the observation that a decrease in capillary density occurred in $\mathrm{p} 43^{-/-}$ mice, in association with the shift toward a faster fiber phenotype in these animals. Overall, taking into account that p43 depletion also affects mitochondrial biogenesis, these data establish that this T3 receptor is deeply involved in the determination of the metabolic and contractile features of muscle fibers, in part by regulating calcineurin expression, as recently published (14).

p43 depletion significantly increased muscle mass. We observed that the mean fibers area was slightly higher in tibialis muscle from $\mathrm{p} 43^{-/-}$mice. As no changes in the total number of muscle fibers were detected, we can rule out hyperplasia However, the significant increase in the number of the biggest fibers occurring in $\mathrm{p} 43^{-/-}$mice clearly suggests that the increased muscle mass resulted essentially from hypertrophy. Interestingly, similar changes in muscle phenotype, including hypertrophy, have been reported after myostatin depletion $(30,31)$, in agreement with the fact that fast fibers generally display a higher area than slow fibers. An intriguing observation is the specific rise in the number of the smallest fibers in the tibialis muscle of $\mathrm{p} 43^{-/-}$mice. This phenotype suggests that $\mathrm{p} 43^{-/-}$mice could have a better ability for muscle regeneration. Further investigation is needed to evaluate the implications of such an effect.
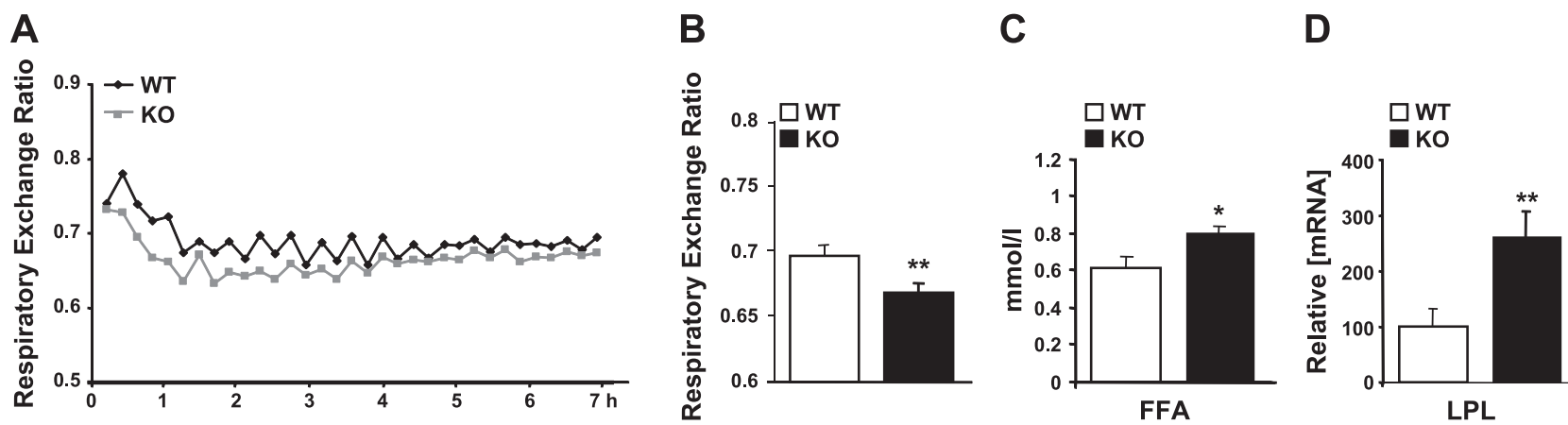

Figure 7. $\mathrm{p} 43^{-/-}$mice had a better capacity to use lipids. A) RER measured at $22^{\circ} \mathrm{C}$ using a Comprehensive Lab Animal Monitoring System (Columbus Instruments). Male mice were acclimatized individually in metabolic cages with ad libitum access to standard chow and water for $24 \mathrm{~h}$ before a 7 -h period of automated recordings in unfed condition. Sample air from individual cages was passed through sensors to determine $\mathrm{O}_{2}$ and $\mathrm{CO}_{2}$ content. RER was assessed by the $\mathrm{CO}_{2}$ production/O $\mathrm{O}_{2}$ consumption ratio. $B$ ) Mean value of the RER recorded during $7 \mathrm{~h}$ in unfed condition. $C$ ) Blood free fatty acid (FFA) levels from control and $\mathrm{p} 43^{-/-}$mice at 5 mo of age $(n=8 /$ group). $D$ ) Lipoprotein lipase (LPL) relative mRNA expression levels in quadriceps muscles from control and $\mathrm{p} 43^{-/-}$mice at 5 mo of age $(n=8 /$ group $)$. Values obtained in $\mathrm{p} 43^{-/-}$mice are expressed as percentage of the corresponding control value. Error bars $=\mathrm{SE} . * P<0.05, * * P<0.01$; Student's $t$ test. 
As expected, we found that $\mathrm{p} 43^{-/-}$mice had a reduced peak velocity at maximal oxygen consumption compared with control animals. This defect could result from the altered muscle mitochondrial biogenesis induced by p43 depletion, causing a decrease in the maximal mitochondrial response to intense exercise. This possibility also agrees with the observation that in prolonged exercise of low intensity performed in the treadmill, the running distance and time displayed by $\mathrm{p} 43^{-/-}$mice were actually improved by $\mathrm{p} 43$ depletion. This is a surprising result that can be explained by the preferential use of fat as an energetic substrate after p43 depletion. Indeed, lipid oxidation is the main energetic pathway used in prolonged exercise of low to moderate intensity in muscle (32). Interestingly, Pelletier et al. (22) have also reported that TR $\alpha$ gene invalidation in mice also favors lipid oxidation relative to carbohydrates. As the $\mathrm{TR} \alpha$ gene simultaneously encodes the nuclear and the mitochondrial T3 receptor, this effect of $\mathrm{TR} \alpha$ gene invalidation could be explained, at least partly, by the simultaneous depletion of p43 expression.

Comparison of the muscle phenotype observed in $\mathrm{p} 43^{-/-}$and TR $\alpha$-deficient mice indicated in both cases a decrease in mitochondrial respiratory chain activities (unpublished results). However, in contrast to our results, no difference in muscle weight was observed in mice lacking TR $\alpha 1$, and this deletion also induced a shift toward a slower muscle fiber phenotype (33). These observations allow us to see the respective effects of the nuclear and mitochondrial T3 pathways, demonstrating either similarity (mitochondriogenesis), difference (muscle weight), or opposite effects (myosin expression), thus indicating that these 2 pathways are complementary and allow a fine-tuning of the thyroid hormone effect.

In summary, these results establish that p43 depletion induces a significant increase in skeletal muscle mass, reduces the extent of mitochondrial biogenesis, and induces a shift toward a more rapid muscle fiber type. Consequently, they highlight that p43 has to be considered as an important regulator of muscle phenotype and activity in vivo. Lastly, the present observation of a better capacity of $\mathrm{p} 43^{-/-}$mice to use lipid in unfed conditions, and our previous data establishing that p43 is an important regulator of glucose homeostasis and pancreatic $\beta$-cell function (17), clearly indicate that this mitochondrial T3 receptor is also an important regulator of whole-body energy metabolism in mice.

The authors thank the animal staff for animal care. The authors thank Chantal Cazevieille (Clinical Research Imaging Centre, Montpellier, France) for technical assistance and interpreting data concerning ultrastructural evaluation. This work was supported by grants from the Institut National de la Recherche Agronomique, Agence Nationale de la Recherche (ANR MitHyCal), and Association Française contre les Myopathies.
1. Booth, F. W., and Thomason, D. B. (1991) Molecular and cellular adaptation of muscle in response to exercise: perspectives of various models. Physiol. Rev. 71, 541-585

2. Olson, E. N., and Williams, R. S. (2000) Calcineurin signaling and muscle remodeling. Cell 101, 689-692

3. Sugie, H., and Verity, M. A. (1985) Postnatal histochemical fiber type differentiation in normal and hypothyroid rat soleus muscle. Muscle Nerve 8, 654-660

4. King, D. B., Bair, W. E., and Jacaruso, R. B. (1987) Thyroidal influence on nuclear accumulation and DNA replication in skeletal muscles of young chickens. J. Exp. Zool. Suppl. 1, 291-298

5. Butler-Browne, G. S., Herlicoviez, D., and Whalen, R. G. (1984) Effects of hypothyroidism on myosin isozyme transitions in developing rat muscle. FEBS Lett. 166, 71-75

6. Izumo, S., and Madhavi, V. (1988) Thyroid receptor a isoform generated by alternative splicing differentially activate MHC gene transcription. Nature 334, 539-542

7. Lazar, M. A. (1993) Thyroid hormone receptors: multiple forms, multiple possibilities. Endocr. Rev. 14, 184-193

8. Brent, G. A., Moore, D. D., and Larsen, P. R. (1991) Thyroid hormone regulation of gene expression. Annu. Rev. Physiol. 53, $17-35$

9. Wrutniak, C., Cassar-Malek, I., Marchal, S., Rascle, A., Heusser, S., Keller, J. M., Flechon, J., Dauca, M., Samarut, J., Ghysdael, J., and Cabello, G. (1995) A 43-kDa protein related to c-Erb A alpha 1 is located in the mitochondrial matrix of rat liver. J. Biol. Chem. 270, 16347-16354

10. Wrutniak-Cabello, C., Casas, F., and Cabello, G. (2001) Thyroid hormone action in mitochondria. J. Mol. Endocrinol. 26, 67-77

11. Casas, F., Rochard, P., Rodier, A., Cassar-Malek, I., MarchalVictorion, S., Wiesner, R. J., Cabello, G., and Wrutniak, C. (1999) A variant form of the nuclear triiodothyronine receptor c-ErbAalphal plays a direct role in regulation of mitochondrial RNA synthesis. Mol. Cell. Biol. 19, 7913-7924

12. Rochard, P., Rodier, A., Casas, F., Cassar-Malek, I., MarchalVictorion, S., Daury, L., Wrutniak, C., and Cabello, G. (2000) Mitochondrial activity is involved in the regulation of myoblast differentiation through myogenin expression and activity of myogenic factors. J. Biol. Chem. 275, 2733-2744

13. Seyer, P., Grandemange, S., Busson, M., Carazo, A., Gamaleri, F., Pessemesse, L., Casas, F., Cabello, G., and WrutniakCabello, C. (2006) Mitochondrial activity regulates myoblast differentiation by control of c-Myc expression. J. Cell. Physiol. 207, 75-86

14. Seyer, P., Grandemange, S., Rochard, P., Busson, M., Pessemesse, L., Casas, F., Cabello, G., and Wrutniak-Cabello, C. (2011) P43-dependent mitochondrial activity regulates myoblast differentiation and slow myosin isoform expression by control of calcineurin expression. Exp. Cell Res. 317, 20592071

15. Casas, F., Pessemesse, L., Grandemange, S., Seyer, P., Gueguen, N., Baris, O., Lepourry, L., Cabello, G., and WrutniakCabello, C. (2008) Overexpression of the mitochondrial T3 receptor $\mathrm{p} 43$ induces a shift in skeletal muscle fiber types. PLoS One 3, e2501

16. Casas, F., Pessemesse, L., Grandemange, S., Seyer, P., Baris, O., Gueguen, N., Ramonatxo, C., Perrin, F., Fouret, G., Lepourry, L., Cabello, G., and Wrutniak-Cabello, C. (2009) Overexpression of the mitochondrial T3 receptor induces skeletal muscle atrophy during aging. PLoS One 4, e5631

17. Blanchet, E., Bertrand, C., Annicotte, J. S., Schlernitzauer, A., Pessemesse, L., Levin, J., Fouret, G., Feillet-Coudray, C., Bonafos, B., Fajas, L., Cabello, G., Wrutniak-Cabello, C., and Casas, F. (2011) Mitochondrial T3 receptor p43 regulates insulin secretion and glucose homeostasis. [Epub ahead of print] FASEB J. doi: 10.1096/fj.11-186841

18. Wang, Y. X., Zhang, C. L., Yu, R. T., Cho, H. K., Nelson, M. C., Bayuga-Ocampo, C. R., Ham, J., Kang, H., and Evans, R. M. (2004) Regulation of muscle fiber type and running endurance by PPARdelta. PLoS Biol. 2, e294

19. Janssen, A. J., Trijbels, F. J., Sengers, R. C., Smeitink, J. A., van den Heuvel, L. P., Wintjes, L. T., Stoltenborg-Hogenkamp, 
B. J., and Rodenburg, R. J. (2007) Spectrophotometric assay for complex I of the respiratory chain in tissue samples and cultured fibroblasts. Clin. Chem. 53, 729-734

20. Rustin, P., Chretien, D., Bourgeron, T., Gerard, B., Rotig, A., Saudubray, J. M., and Munnich, A. (1994) Biochemical and molecular investigations in respiratory chain deficiencies. Clin. Chim. Acta 228, 35-51

21. Wharton, D. (1967) Cytochrome oxidase from beef heart mitochondria. Meth. Enzymol. 10, 245-250

22. Pelletier, P., Gauthier, K., Sideleva, O., Samarut, J., and Silva, J. E. (2008) Mice lacking the thyroid hormone receptor-alpha gene spend more energy in thermogenesis, burn more fat, and are less sensitive to high-fat diet-induced obesity. Endocrinology 149, 6471-6486

23. Larsson, N. G., Wang, J., Wilhelmsson, H., Oldfors, A., Rustin, P., Lewandoski, M., Barsh, G. S., and Clayton, D. A. (1998) Mitochondrial transcription factor $\mathrm{A}$ is necessary for mtDNA maintenance and embryogenesis in mice. Nat. Genet. 18, 231-236

24. Wredenberg, A., Wibom, R., Wilhelmsson, H., Graff, C., Wiener, H. H., Burden, S. J., Oldfors, A., Westerblad, H., and Larsson, N. G. (2002) Increased mitochondrial mass in mitochondrial myopathy mice. Proc. Natl. Acad. Sci. U. S. A. 99, 15066-15071

25. Lansman, R. A., and Clayton, D. A. (1975) Mitochondrial protein synthesis in mouse L-cells: effect of selective nicking of mitochondrial DNA. J. Mol. Biol. 99, 777-793

26. England, J. M., Costantino, P., and Attardi, G. (1978) Mitochondrial RNA and protein synthesis in enucleated African green monkey cells. J. Mol. Biol. 119, 455-462
27. Ausoni, S., Gorza, L., Schiaffino, S., Gundersen, K., and Lomo, T. (1990) Expression of myosin heavy chain isoforms in stimulated fast and slow rat muscles. J. Neurosci. 10, $153-160$

28. Mathieu-Costello, O., Ellis, C. G., Potter, R. F., MacDonald, I. C., and Groom, A. C. (1991) Muscle capillary-to-fiber perimeter ratio: morphometry. Am. J. Physiol. Heart Circ. Physiol. 261, H1617-H1625

29. McDonald, K. S., Delp, M. D., and Fitts, R. H. (1992) Fatigability and blood flow in the rat gastrocnemius-plantaris-soleus after hindlimb suspension. J. Appl. Physiol. 73, 1135-1140

30. Girgenrath, S., Song, K., and Whittemore, L. A. (2005) Loss of myostatin expression alters fiber-type distribution and expression of myosin heavy chain isoforms in slow- and fast-type skeletal muscle. Muscle Nerve 31, 34-40

31. Zhu, X., Hadhazy, M., Wehling, M., Tidball, J. G., and McNally, E. M. (2000) Dominant negative myostatin produces hypertrophy without hyperplasia in muscle. FEBS Lett. 474, $71-75$

32. Holloszy, J. O., and Coyle, E. F. (1984) Adaptations of skeletal muscle to endurance exercise and their metabolic consequences. J. Appl. Physiol. 56, 831-838

33. Yu, F., Gothe, S., Wikstrom, L., Forrest, D., Vennstrom, B., and Larsson, L. (2000) Effects of thyroid hormone receptor gene disruption on myosin isoform expression in mouse skeletal muscles. Am. J. Physiol. Regul. Integr. Comp. Physiol. 278, R1545-R1554

Received for publication September 8, 2011. Accepted for publication October 13, 2011. 